\title{
ALGUNAS NOTAS SOBRE LOS SUCESIVOS ESTADOS DE ALARMA DECLARADOS EN 2020
}

Luis Pomed Sánchez

Letrado del Tribunal Constitucional

Cómo citar este artículo / Citation: Pomed Sánchez, L. (2021). Algunas notas sobre los sucesivos estados de alarma declarados en 2020. Tudela Aranda, J. (coord.)

Estado Autonómico y covid-19, Colección Obras colectivas, Fundación Manuel Giménez Abad, Zaragoza. DOI: https://doi.org/10.47919/FMGA.OC21.0210

SUMARIO: I. INTRODUCCIÓN - II. BREVE REFERENCIA A LA REGULACIÓN LEGAL DEL ESTADO DE ALARMA - III. TRES MODALIDADES DEL ESTADO DE ALARMA - 1. EI RD alarma-1: estado de alarma en el supuesto y de excepción en las consecuencias - 2 . Interludio madrileño: el RD alarma-2 - 3. El Estado autonómico de emergencia: RD alarma-3 - IV. CONCLUSIONES

\section{INTRODUCCIÓN}

La Organización Mundial de la Salud elevó el pasado 11 de marzo de 2020 la situación de emergencia de salud pública ocasionada por el COVID-19 a pandemia internacional. Con esta frase, compuesta de apenas veintiocho palabras, pero cuya sola lectura corta el aliento, se inicia la parte expositiva de los tres reales decretos de declaración del estado de alarma que se han sucedido en el último año: Real Decreto 463/2020, de 14 de marzo, por el que se declara el estado de alarma para la gestión de la crisis sanitaria ocasionada por el COVID-19 (en adelante, RD alarma-1); Real Decreto 900/2020, de 9 de octubre, por el que se declara el estado de alarma para responder ante situaciones de especial riesgo por transmisión no controlada de infecciones causada por el SARCoV-2 (en adelante, RD alarma-2) y, en fin, Real Decreto 
926/2020, de 25 de octubre, por el que se declara el estado de alarma para contener la propagación de infecciones causadas por el SARS-CoV-2 (en adelante, RD alarma-3). Este último sigue vigente al momento de redactar estas líneas como consecuencia de su prórroga por el Real Decreto 956/2020, de 3 de noviembre.

Si bien se ha acudido a una misma figura de emergencia, el estado de alarma, las diferencias en la situación resultante de las sucesivas declaraciones (en particular, si se comparan RD alarma-1 y RD alarma-39) invitan a preguntarse si en verdad existe un régimen jurídico unitario del estado de alarma en nuestro país, o si, por el contrario, nos hallamos ante una categoría sumamente dúctil. Hasta el punto de que podría sostenerse que la principal virtud de la figura consistiría, justamente, en su capacidad de adaptación a las circunstancias que debe enfrentar.

\section{BREVE REFERENCIA A LA REGULACIÓN LEGAL DEL ESTADO DE ALARMA}

Como bien advirtiera en su Memoria el proyecto de ley de la que acabaría siendo Ley Orgánica reguladora de los estados de alama, excepción y sitio (LOEAES), la denominación "estado de alarma", aunque coincidente con una de las utilizadas por la Ley de orden público de 28 de julio de 1933, "responde ahora a una realidad distinta", pues "el estado de alarma de la ley republicana es homólogo propiamente del estado de excepción, según la concepción de la Ley [de orden público] de 1959, y según el proyecto [que entonces se presentaba y que ahora es la Ley Orgánica 4/1981, de 1 de junio]".

Importa recordar que el proyecto de ley remitido por el Gobierno se titulaba "de Seguridad Ciudadana" y que, siguiendo la tradición legislativa en la materia -de la que son buena muestra las leyes republicana y franquista de orden público-, su articulado comprendía tanto las facultades públicas ordinarias como las extraordinarias en la materia. Sin embargo, la tramitación parlamentaria del proyecto redujo el texto legal a las segundas (la regulación legal de las facultades ordinarias habría de esperar hasta la aprobación de las leyes orgánicas de seguridad ciudadana de 1992 y 2015), quedando igualmente por 
el camino la memoria que acompañaba al texto remitido por el Gobierno a las cámaras legislativas y que no se convirtió en preámbulo.

Sea como fuere, esa misma memoria gubernamental indicaba que los supuestos determinantes de la declaración del estado de alarma (enumerados ahora en el art. 4 LOEAES) tenían el denominador común de que "en ellos peligra la seguridad o la salud de las personas, o se encuentra en riesgo grave el mantenimiento de las condiciones físicas necesarias para el desenvolvimiento de la vida de la colectividad". El proyecto trataba así de dotar de entidad propia a una figura, el estado de alarma, enunciada en la Constitución y apenas definida en la norma fundamental, más por referencia a aquello que cabalmente no es (un estado de emergencia cuya declaración no permite suspender derechos fundamentales ex artículo 55.1 CE a contrario) que por su contenido efectivo (respecto del cual, el artículo 116.1 CE apenas afirma la competencia gubernamental para la declaración inicial, con vigencia limitada a quince días, y la supeditación de la prórroga al otorgamiento previo de la autorización por el Congreso de los Diputados). De hecho, fueron varias las enmiendas presentadas al entonces artículo 94 del Anteproyecto de Constitución que postularon la eliminación del estado de alarma, figura sin contenido, que, en palabras de Simón Sánchez Montero, no tiene razón de ser, ya que el Gobierno tiene facultades suficientes para enfrentarse a situaciones de anormalidad no graves, sin limitar las libertades públicas, y en el caso de que lo sean está el estado de excepción.

La relativa indefinición de que adolecía la figura del estado de alarma en nuestro ordenamiento jurídico se redujo por efecto de la doctrina constitucional sentada en el ATC 7/2012, de 13 de enero, y la STC 83/2016, de 28 de abril, resoluciones ambas en las que el Tribunal Constitucional hubo de enfrentarse con alguno de los problemas suscitados por el Real Decreto 1673/2010, de 4 de diciembre, por el que se declara el estado de alarma para la normalización del servicio publico esencial del transporte aéreo, cuya vigencia se prorrogó por el Real Decreto 1717/2010, de 17 de diciembre. De esa doctrina interesa recordar ahora los siguientes extremos:

a) El estado de alarma es una de las figuras del Derecho constitucional de excepción dispuesta por el constituyente para "hacer frente a posibles situaciones de anormalidad constitucional" (STC 83/2016, FJ 7). Esta reconducción de la figura al Derecho constitucional de 
excepción permite afirmar que participa, junto con los estados de excepción y sitio, siquiera sea en menor medida, de las características definidoras de esa misma excepcionalidad: amparando la modificación del régimen de ejercicio ordinario de competencias y permitiendo el establecimiento de un régimen de restricciones de los derechos individuales, efectos ambos que tienen como sustrato común la fuerza activa de ley del acto de declaración.

b) En cuanto a lo primero, la declaración del estado de alarma supone la concentración de atribuciones en el Gobierno de la Nación (STC 83/2016, FJ 8).

c) Respecto de lo segundo, y "a diferencia [de lo que sucede en] los estados de excepción y de sitio, la declaración del estado de alarma no permite la suspensión de ningún derecho fundamental (art. 55.1 CE contrario sensu), aunque sí la adopción de medidas que pueden suponer limitaciones o restricciones a su ejercicio" (ibidem).

d) El acto de declaración del estado de emergencia, y la autorización parlamentaria de su prórroga, tienen fuerza activa de ley y consecuentemente alteran el sistema ordinario de fuentes del ordenamiento. De acuerdo con lo afirmado en el ATC 7/2012, FFJJ 3 y 4, y en la STC 83/2016, FJ 9, todos los estados de emergencia "y también por tanto, el de menor intensidad de entre ellos, esto es, el de alarma, suponen, como es evidente y así resulta de su regulación en la Ley Orgánica 4/1981, de 4 de junio, de los estados de alarma, excepción y sitio, excepciones o modificaciones pro tempore en la aplicabilidad de determinadas normas del ordenamiento vigente, incluidas, en lo que ahora importa, determinadas disposiciones legales, que sin ser derogadas o modificadas sí pueden ver alterada su aplicabilidad ordinaria [...] pues el fundamento de la declaración de cualquiera de estos estados es siempre la imposibilidad en que se encuentran las autoridades competentes para mantener mediante 'los poderes ordinarios' la normalidad ante la emergencia de determinadas circunstancias extraordinarias (art. 1.1 de la Ley Orgánica 4/1981, de 4 de junio, de los estados de alarma, excepción y sitio)". 
De donde se concluye que el acto de declaración, con valor de ley, tiene la apuntada fuerza activa de ley puesto que "la decisión gubernamental por la que se declara el estado de alarma no se limita a constatar el presupuesto de hecho habilitante de la declaración de dicho estado, esto es, la concurrencia de alguna o algunas de las situaciones o 'alteraciones graves de la normalidad' previstas en la Ley Orgánica 4/1981 (art. 4) que pueden dar lugar a la proclamación del estado de emergencia, ni se limita tampoco a la mera declaración de este. La decisión gubernamental tiene además un carácter normativo, en cuanto establece el concreto estatuto jurídico del estado que se declara. En otras palabras, dispone la legalidad aplicable durante su vigencia, constituyendo también fuente de habilitación de disposiciones y actos administrativos. La decisión gubernamental viene así a integrar, en cada caso, sumándose a la Constitución y a la Ley Orgánica 4/1981, el sistema de fuentes del derecho de excepción, al complementar el derecho de excepción de aplicación en el concreto estado declarado. $\mathrm{Y}$ esta legalidad excepcional que contiene la declaración gubernamental desplaza durante el estado de alarma la legalidad ordinaria en vigor, en la medida en que viene a excepcionar, modificar o condicionar durante ese periodo la aplicabilidad de determinadas normas, entre las que pueden resultar afectadas leyes, normas o disposiciones con rango de ley, cuya aplicación puede suspender o desplazar" (STC 83/2016, FJ 10).

De modo que no era poco, sin ser tampoco mucho, lo que sabíamos a ciencia cierta del estado de alarma el 13 de marzo de 2020, esto es, un día antes de que volviera a recurrirse a esta figura del Derecho de emergencia: su declaración tiene lugar por un acto con fuerza activa de ley que produce una alteración pro tempore en la aplicabilidad de algunas normas jurídicas; supone una concentración de atribuciones en el Gobierno de la Nación, la denominada "unidad de mando"; y puede limitar, que no suspender, el ejercicio de la libertad deambulatoria ex art. 10 a) LOEAES. Cabe preguntarse si después de un año viviendo habitualmente en estado de alarma sabemos más acerca de esta y es dudoso que las certezas de antaño sigan siendo tales. 


\section{TRES MODALIDADES DEL ESTADO DE ALARMA}

En el último año se han sucedido hasta tres declaraciones de estados de alarma, si bien únicamente en la Comunidad de Madrid han estado vigentes todos ellos. La sucesión de declaraciones lo ha sido igualmente de subespecies de esta modalidad de estado de emergencia.

\section{El RD alarma-1: estado de alarma en el supuesto y de excepción en las consecuencias}

El preámbulo del RD alarma-1 justificaba el recurso al Derecho de emergencia en la inevitabilidad de la declaración del estado de alarma ("Para hacer frente a esta situación, grave y excepcional, es indispensable proceder a la declaración del estado de alarma"). La aseveración de la necesidad de la declaración venía acompañada de una defensa de la proporcionalidad lato sensu de las medidas adoptadas:

Las medidas que se contienen en el presente real decreto son las imprescindibles para hacer frente a la situación, resultan proporcionadas a la extrema gravedad de la misma y no suponen la suspensión de ningún derecho fundamental, tal y como prevé el artículo 55 de la Constitución.

A) El confinamiento domiciliario: una suspensión de la libertad deambulatoria

Toda vez que el objetivo perseguido con la declaración del estado de alarma era la contención de la expansión del virus y comoquiera que ese propósito solo se podía lograr reduciendo a su menor e imprescindible expresión la movilidad de la población, la principal de esas "medidas imprescindibles" consistió, como bien sabemos, en el confinamiento domiciliario de los ciudadanos. Una medida que se concretaba en el artículo 7 del RD alarma-1.

Advertía el apartado primero de ese artículo 7 del RD alarma-1, verdadera piedra basilar del régimen de emergencia, que "durante la vigencia del estado de alarma las personas únicamente podrán circular por las vías de uso público para la realización de las [...] actividades" que seguidamente se enumeraban con vocación de exhaustividad (adquisición de alimentos, productos farmacéuticos y de primera necesidad; asistencia a centros, servicios y 
establecimientos sanitarios; desplazamientos de carácter laboral; retorno al lugar de residencia habitual; asistencia a personas de colectivos vulnerables; desplazamientos a entidades crediticias y de seguros, o por causa de fuerza mayor o situación de necesidad), hasta el punto de que el precepto se completaba con una cláusula de cierre que en efecto lo era: "Cualquier otra actividad de análoga naturaleza[,] que habrá de hacerse individualmente, salvo que se acompañe a personas con discapacidad o por otra causa justificada".

Que el arma principal en la lucha contra la covid-19 era la reducción de la movilidad ciudadana se pone de relieve cuando reparamos en que lo previsto en el artículo 7 cobraba pleno sentido en el marco de las distintas suspensiones de actividad acordadas en el RD alarma-1, que recibían el nombre de "medidas de contención", pues tal era el objetivo propiamente perseguido. Así, se suspendió toda la actividad docente presencial en los diferentes niveles de enseñanza (art. 9), cultural, comercial, recreativa, de hostelería y restauración (art. 10 y anexo) y se redujo la frecuencia de las distintas modalidades de transporte público de viajeros (art. 14).

Es el confinamiento domiciliario universal de la población, decisión nuclear del RD alarma-1, la medida cuya adecuación al marco constitucional regulador del estado de alarma suscita mayores reparos.

Al respecto debe recordarse, una vez más, que ex artículo 55.1 CE a contrario sensu, la declaración del estado de alarma no puede conllevar la suspensión del ejercicio de ningún derecho fundamental. Ni tan siquiera de la libertad de circulación del artículo 19 CE, cuya suspensión sí que es posible en la declaración de las otras dos categorías de estados de emergencia. Respetuosa con ese límite constitucional infranqueable, la LOEAES permite en su artículo 11 que el decreto de declaración del estado de alarma acuerde, entre otras, las siguientes medidas: “a) Limitar la circulación o permanencia de vehículos en horas y lugares determinados, o condicionarlas al cumplimiento de ciertos requisitos".

Parece difícil imaginar que haya podido otorgarse la calificación de simple "limitación" de la libertad de circulación al confinamiento de cuarenta y siete millones de residentes (exactamente, 47.332.614, según los datos a 1 de enero de 2020 proporcionados por el Instituto Nacional de Estadística) en sus domicilios. Y, sin embargo, así ha sido. Han abundado los defensores de esta 
interpretación, acaso conscientes de las insuficiencias y carencias de un Derecho constitucional de excepción que, al menos por lo que se refiere a la lucha contra la covid-19, se ha movido entre el supuesto de hecho habilitante de la declaración del estado de alarma [una de las "crisis sanitarias, tales como epidemias" mencionadas en el artículo 4 b) LOEAES] y la medida principal adoptada para hacer frente a la situación de emergencia, que solo puede ser calificada como una auténtica suspensión de la libertad deambulatoria proclamada por el artículo 19 de la Constitución. Estamos, por tanto, ante un estado de alarma por la alteración grave de la normalidad, a la que no puede hacerse frente con los medios ordinarios del Estado, y de excepción por el régimen jurídico adoptado. Con la particularidad de que en el estado de excepción la intervención parlamentaria no solo es previa a la declaración (art. 116.3 CE) sino más intensa, pues en la solicitud de autorización el Gobierno debe incluir una "mención expresa" de aquellos derechos fundamentales cuya suspensión pretende llevar a efecto [art. 13.2 a) LOEAES]. Convendría no minusvalorar las garantías que preceden y acompañan al estado de excepción, cuya vigencia tiene -a diferencia de lo que sucede con el estado de alarma- un límite absoluto (art. 116.3 in fine CE).

Si los derechos fundamentales son la máxima expresión de la vinculación negativa de los ciudadanos a la ley, de modo que aquellos pueden hacer todo aquello que esta no prohíba, podemos añadir que el artículo 7 RD alarma-1 volteó esta situación y sometió a los ciudadanos a un régimen de vinculación positiva, de suerte que solo podían abandonar sus domicilios cuando podían invocar lícitamente uno de los motivos tasados que figuraban en el primer apartado de ese precepto. No se trataba, recuérdese, de "limitar la circulación o permanencia de personas o vehículos en horas y lugares determinados" como preveía el artículo 11 a) LOEAES, sino de imponer la permanencia de todas las personas en un lugar determinado y durante todo el tiempo que rigiera el confinamiento domiciliario. Se negaba con ello la posibilidad de ejercer la libertad de circulación, cuyo contenido esencial no es otro que el de poder desplazarse libremente -esto es, sin necesidad de argüir motivo alguno- por las vías públicas. La circulación dejó de ser un derecho de libertad susceptible de limitación justificada para convertirse en una facultad deambulatoria que solo se podía ejercer cuando concurriera un motivo justificado y así lo apreciara eventualmente la autoridad competente. 
Cierto es que el RD alarma-1 limitaba el ejercicio de un derecho fundamental, pero no era la libertad de circulación sino de culto. En efecto, su artículo 11 condicionó la asistencia a los lugares de culto y a las ceremonias civiles y religiosas "a la adopción de medidas organizativas consistentes en evitar aglomeraciones de personas, en función de las dimensiones y características de los lugares, de tal manera que se garantice a los asistentes la posibilidad de respetar la distancia entre ellos de, al menos, un metro". De modo que podían seguir celebrándose esos actos de culto y las ceremonias a las que se aludía en el precepto, pese a que pudiera limitarse la asistencia de fieles 0 interesados.

No faltaron voces que alertaron acerca del difícil encaje constitucional de la medida ${ }^{1}$. Pero, quizás, fueron los más quienes trataron de lograr esa cuadratura del círculo. De tal cabe hablar si pensamos en que las categorías del Derecho constitucional de emergencia no cubren supuestos como el que debió enfrentar el RD alarma-1 pues existe una cesura diríase que insalvable entre el estado de alarma, que permite limitar, pero no suspender, derechos fundamentales, y el estado de excepción, figura que habilita el uso de facultades extraordinarias y en particular la suspensión de algunos derechos fundamentales. Cuando la crisis sanitaria es de tal magnitud que el confinamiento domiciliario se presenta como una medida absolutamente necesaria, resulta comprensible que el Gobierno de turno se mueva con inseguridad entre el Caribdis del estado de alarma y la Escila del estado de excepción.

Para sortear esos dos peligros cabe hacer una interpretación del supuesto habilitante del estado de excepción que ponga el acento en la grave alteración de la normal prestación del servicio público esencial de la sanidad (art. 13.1

\footnotetext{
${ }^{1}$ A los autores expresamente citados por Juan Alfonso Santamaría Pastor, "Notas sobre el ejercicio de las potestades normativas en tiempos de pandemia", en David Blanquer (coordinador), COVID-19 y Derecho público (durante el estado de alarma y más allá), Tirant lo Blanch, Valencia, 2020, pp. 207 y ss. [Miguel Ángel Presno Linera (https://presnolinera.wordpress.com/2020/03/14/breves-y-provisionales-consideraciones-sobreel-alcance-del-estado-de-alarma-que-se-va-a-decretar/), Juan Manuel Alegre Ávila y Ana Sánchez Lamelas (http://www.aepda.es/AEPDAEntrada-2741-Nota-en-relacion-a-la-crisissanitaria-generada-por-la-actual-emergencia-virica.aspx) y Francisco Javier Díaz Revorio (https://javierdiazrevorio.com/cosas-de-juristas/), es preciso añadir el nombre de Manuel Aragón Reyes, "Hay que tomarse la Constitución en serio", El País, 10 de abril de 2020. Disponible en: https://elpais.com/elpais/2020/04/09/opinion/1586420090_736317.html. En sentido contrario, por todos y en ese mismo libro colectivo, Francisco Velasco Caballero, "Libertades públicas durante el estado de alarma por la COVID-19", pp. 79 y ss.
} 
LOEAES), o hacer uso intensivo de las facultades extraordinarias a que alude la legislación sanitaria.

Cierto es que la primera posibilidad habría permitido articular un estado de excepción de duración limitada a un máximo de dos meses (el estado de alarma se prolongó hasta las 00:00 horas del 21 de junio de 2020, sumando tres meses y siete días de vigencia desde el 14 de marzo de ese mismo año), con eventuales desescaladas mediante el recurso al estado de alarma, pues el levantamiento del confinamiento domiciliario habría salvado cualquier duda de constitucionalidad. Pero no es menos cierto que sigue pesando en el inconsciente colectivo una resistencia más que justificable a hacer uso del estado de excepción. Ni nuestra historia constitucional ni el momento por el que atraviesan nuestras instituciones políticas y la convivencia social eran las adecuadas para apostar en marzo de 2020 por una declaración del estado de excepción y acudir con la petición correspondiente a un Congreso de los Diputados cuya composición no invitaba precisamente a vislumbrar con optimismo el resultado final de la tramitación parlamentaria de la solicitud gubernamental.

La utilización de la legislación sanitaria habría situado acaso el problema en sus justos términos: el de una crisis de salud pública y de subsistencia de la sanidad. Pero hubiera tenido en su contra la imprecisión de las habilitaciones a las autoridades sanitarias habitual en esa legislación. Hasta el extremo de que en el caso concreto de la eventual obligatoriedad de las vacunas contra la covid-19 es más adecuado buscar su fundamento en la base 4.6 de la Ley de bases de la Sanidad Nacional de 25 de noviembre de 1944 -obviamente, en la redacción dada por la Ley 22/1980, de 24 de abril- que hacerlo en la Ley Orgánica 3/1986, de 14 de abril, de medidas especiales de salud pública, cuyo artículo 3 constituye una habilitación en blanco a las autoridades sanitarias, que para controlar las enfermedades transmisibles "además de realizar las acciones preventivas generales, podrá adoptar las medidas oportunas para el control de los enfermos, de las personas que estén o hayan estado en contacto con los mismos y del medio ambiente inmediato, así como las que se consideren necesarias en caso de riesgo de carácter transmisible". No parece que los términos empleados en el precepto faciliten precisamente la fiscalización del adecuado ejercicio de la habilitación que contiene. 


\section{B) Las autoridades delegadas}

La adecuación de la categoría del estado de alarma al Estado autonómico no ha sido fácil. En RD alarma-1 no se contemplaba la intervención de las comunidades autónomas en la gestión de la pandemia, al menos hasta la prórroga por el Real Decreto 514/2020, de 8 de mayo, que abrió la puerta a la colaboración en el proceso de desescalada hacia la "nueva normalidad".

La concentración de atribuciones en el Gobierno de la Nación dejó al margen, en particular, a los responsables ordinarios —las comunidades autónomasde la gestión sanitaria. La recuperación de las funciones de gestión por la Administración del Estado no siempre se saldó con éxito, lo que bien puede comprenderse si reparamos en la transformación que la Administración General del Estado ha sufrido en los cuarenta años de vigencia de la LOEAES. No es ya una administración de gestión sino eminentemente de planificación. Por eso la unidad de mando vino acompañada de la interlocución, no siempre fructífera, con los responsables políticos autonómicos y con los gestores de las comunidades autónomas.

Al margen de lo anterior, sorprende el hecho de que el RD alarma-1 atribuyera la consideración de "autoridades competentes delegadas", en el ámbito de sus respectivas áreas de responsabilidad, a los titulares de los Ministerios de Defensa, Interior, Sanidad y Transportes, Movilidad y Agenda Urbana (art. 4.2). Parece que el RD alarma-1 renunció a crear una comisión interministerial o gabinete de crisis, pero no se entiende muy bien la delegación reflexiva del Gobierno en sus propios integrantes y no deja de resultar problemática esta decisión cuando se contrasta con el artículo 7 LOEAES, que es tajante al identificar como autoridad competente delegada al presidente de la Comunidad Autónoma cuando la declaración afecta exclusivamente a todo o parte del territorio de una Comunidad. Es posible que ni tan siquiera estemos ante una auténtica delegación, hipótesis que se vería reforzada por la paradoja de delegar en unos ministros que actúan "en sus respectivas áreas de responsabilidad" (art. 4.2 RD alarma-1).

Quede constancia, finalmente, de que la vigencia del estado de emergencia declarado por el RD alarma-1 fue un período de extraordinaria producción normativa gubernamental. Baste recordar que la vigencia del propio RD alarma-1 fue prorrogada, por otros seis reales decretos, hasta el 21 de junio de 
2020 (todas las prórrogas fueron autorizadas por el Congreso de los Diputados, salvo la acordada en el Real Decreto 555/2020, de 5 de junio, con cuya expiración decayó el estado de alarma). O que, durante ese período y con el fin de hacer frente a la pandemia, se dictaron catorce reales decretos leyes, once reales decretos ${ }^{2} \mathrm{y}$ algo más de un centenar de órdenes ministeriales (hasta 116 se recopilan en el Código electrónico confeccionado por el Boletín Oficial del Estado). Durante ese tiempo se publicaron veinticuatro números extraordinarios del diario oficial, una práctica hasta entonces prácticamente inédita.

\section{Interludio madrileño: el RD alarma-2}

El levantamiento del estado de emergencia declarado por RD alarma-1 coincidió con una ligera tregua en la pandemia, que bien pudo haber sido aprovechada para que el ausente Poder Legislativo recuperase el protagonismo que le es propio en una "Monarquía parlamentaria". Era ocasión, quizás, para abordar una reforma de la Ley Orgánica 3/1986 y completar algo más las imprecisas pautas y criterios de actuación de las autoridades sanitarias, a cuyo prudente arbitrio parece quedar la determinación de qué "medidas" sean "oportunas y necesarias", conceptos que proporcionan escasa seguridad en la construcción de un canon de control de la acción administrativa. La reforma podría haberse completado con un diseño más preciso de los supuestos en los que es necesaria la autorización judicial para la ejecución de las medidas por su eventual incidencia en los derechos fundamentales de los ciudadanos.

El poder legislativo intervino, pero en lugar de establecer por sí mismo las medidas y prever la autorización judicial para su ejecución, incorporó la intervención judicial a la adopción de las medidas. La Ley 3/2020, de 18 de septiembre, de medidas procesales y organizativas para hacer frente al

\footnotetext{
${ }^{2}$ Bien es cierto que en alguna ocasión la pandemia fue la ocasión aducida para reformas organizativas que nada tenían que ver con el coronavirus. Así sucedió en el caso del Real Decreto-ley 8/2020, de 17 de marzo, de medidas urgentes extraordinarias para hacer frente al impacto económico y social del COVID-19, que, inopinadamente, modificó la composición de la comisión delegada del Gobierno para asuntos de inteligencia, recogida en el artículo 6 de la Ley reguladora del Centro Nacional de Inteligencia, lo que, a su vez, hizo necesaria la reforma del Real Decreto 399/2020, de 25 de febrero, por el que se establecen las comisiones delegadas del Gobierno, que se llevó a cabo por el Real Decreto 464/2020, de 17 de marzo. No es fácil establecer la conexión de sentido que enlaza la situación de extraordinaria y urgente necesidad aducida para aprobar el decreto-ley en cuestión (la situación de pandemia mundial) con la medida estrictamente organizativa y ajena al ámbito de actuación sanitaria y asistencial, adoptada en la disposición final segunda del Real Decreto-ley 8/2020.
} 
COVID-19 en el ámbito de la Administración de Justicia, modificó la Ley de la jurisdicción contencioso-administrativa para atribuir a los juzgados de ese orden jurisdiccional la autorización o ratificación de "medidas adoptadas con arreglo a la legislación sanitaria que [...] impliquen limitación o restricción de derechos fundamentales" cuando "estén plasmadas en actos administrativos singulares que afecten únicamente a uno o varios particulares concretos $\mathrm{e}$ identificados de manera individualizada" (art. 8.6 LJCA) y a las salas de los tribunales superiores de justicia la autorización o ratificación de esas medidas "cuando sus destinatarios no estén identificados individualmente" (art. 10.8 LJCA).

Al hablarse de "medidas", la previsión del nuevo artículo 10.8 de la ley jurisdiccional abría un horizonte confuso y conflictivo. La autorización o ratificación podía serlo de normas reglamentarias, al menos de reglamentos autoaplicativos (la alusión a medidas "urgentes y necesarias" invita a pensar que la intervención judicial no alcanza a los reglamentos que no tengan esta naturaleza). Se ha dado así entrada a la participación de los jueces en el ejercicio de la potestad reglamentaria, configurándose su intervención como un mecanismo de protección universal de los derechos fundamentales, cuando cabe dudar de que esto sea así y de que no provoque desajustes en el ejercicio de otros derechos fundamentales.

En primer lugar, habrá que reparar en que no es lo mismo establecer un cauce procesal para hacer efectiva la garantía jurisdiccional de algunos derechos fundamentales (arts. 17 y $18 \mathrm{CE}$, en particular) que extender esa misma garantía a todos los supuestos de afectación a derechos fundamentales. Porque no es igual la incidencia en el derecho fundamental mediante una actuación material -entrada en domicilio-, que a través de una norma jurídica con vocación de generalidad, innovación y permanencia, al menos mientras duren las circunstancias que puedan invocarse para su aprobación. En el primero de los casos, la autorización judicial lo es de la ejecución estricta de la resolución administrativa contrastándola con el derecho fundamental en conflicto mediante un examen estricto, ahí sí, de la necesidad, adecuación y proporcionalidad en sentido estricto de la forma de ejecución. Por el contrario, en el segundo se invita al juez a hacer un juicio sobre la idoneidad de los instrumentos para alcanzar los fines perseguidos con las medidas. 
No deja de incidir el ejercicio de esta potestad de ratificación o autorización -por cierto, que la autorización será en todo caso previa y requisito de validez, cuando no de existencia, de la norma, y la ratificación posterior a la ejecución misma de la "medida"- en las garantías procesales de un eventual control judicial posterior de lo ratificado o autorizado. Piénsese en aquellos tribunales superiores de justicia con una sala de lo contencioso-administrativo, de sección única: ¿no existirán dudas acerca de la apariencia de imparcialidad de quienes han de conocer en recurso directo contra la norma si esas mismas personas la ratificaron o autorizaron?, ¿ratificaron o autorizaron la entrada en vigor, esto es, su eficacia, de la norma, o su puesta en práctica? Obviamente, la ratificación o autorización no sana los vicios de la norma, pero es lo cierto que, a diferencia de la autorización de actos de ejecución, es discutible que aquí nos encontremos ante un requisito de eficacia de la "medida".

Se ha apuntado que detrás de esta habilitación legislativa a la intervención judicial en el gobierno de la crisis sanitaria se ocultaría un cierto miedo a gobernar. Es lo cierto, sin embargo, que esa intervención judicial no cambia la naturaleza de una medida que, en tanto que disposición de carácter general, se incardina en la esfera de acción del Gobierno autonómico. No es menos cierto que, con mayor o menor tino, el legislador vino a establecer otro mecanismo de control de la acción administrativa y que, consecuentemente, en uso de esa habilitación los órganos judiciales podían no ratificar o autorizar la medida cuando entendieran que la afectación a los derechos fundamentales era desproporcionada.

Esto fue lo que sucedió con la Orden de la Consejería de Sanidad de la Comunidad de Madrid 1273/2020, de 1 de octubre, por la que se establecen medidas preventivas en determinados municipios de la Comunidad de Madrid en ejecución de la Orden del Ministro de Sanidad, de 30 de septiembre de 2020, por la que se aprueban actuaciones coordinadas en salud pública. La Sección Octava de la Sala de lo Contencioso-Administrativo del Tribunal Superior de Justicia de la Comunidad de Madrid, en su auto 128/2020, de 8 de octubre, denegó la ratificación de dichas medidas en cuanto afecten a derechos y libertades fundamentales, según reza textualmente la parte dispositiva del auto.

Ante la situación creada y de manera inmediata, se dictó el RD alarma-2 al día siguiente de que se pronunciara el auto. Esta nueva declaración puso de 
manifiesto la virtualidad, en el entendimiento gubernamental, del estado de emergencia para evitar los problemas que pueda suscitar la autorización judicial de medidas adoptadas una vez expirada la vigencia del estado de alarma. Distinto será el caso de denegación de la autorización o ratificación judicial de medidas acordadas durante la vigencia de un estado de alarma previamente declarado y que no suspenda temporalmente la aplicabilidad del artículo 10.8 LJCA.

EI RD alarma-2 estableció una auténtica limitación de la libertad deambulatoria mediante el confinamiento perimetral de la población residente en los nueve municipios de la Comunidad de Madrid mencionados en su artículo 2, salvo que concurriera alguna de las causas de justificación recogidas en el artículo 5, que reproducía el artículo 7 de RD alarma-1. En este caso, la libertad de circulación se limitaba a lugares concretos, sin negarse absolutamente, salvo que mediara un motivo justificado, como se hiciera en RD alarma-1.

El estado de emergencia declarado por RD alarma-2 no fue prorrogado y quedó como manifestación de un modo de resolver los problemas suscitados por la falta de ratificación judicial de las medidas que se pretendían adoptar mediante una orden administrativa, y de saltar por encima de los desencuentros entre gobiernos de distinto signo. Como ya se ha indicado, su incidencia sobre la libertad de circulación no puede rebasar el marco de una limitación acorde con la previsión del artículo 11 LOEAES.

\section{El estado autonómico de emergencia: RD alarma-3}

La experiencia vivida durante la vigencia de RD alarma-1 aconsejaba, como ya se ha apuntado, una revisión en profundidad de la legislación sanitaria a fin de poder hacer frente con ella a las sucesivas olas de la pandemia, cuya llegada era, por desgracia, tan previsible como inevitable. Mencionada esta posibilidad en el epígrafe anterior, puede añadirse que la tregua que el coronavirus nos dio durante los meses del verano también podría haberse aprovechado para una reforma en profundidad del Derecho constitucional de excepción. Era el momento de adaptar el estado de alarma al Estado autonómico. En particular porque durante la vigencia de la LOEAES se ha consolidado la estructura territorial descentralizada y las diferentes comunidades autónomas han hecho uso de las posibilidades que les ha brindado una nueva materia, la protección civil, que les ha permitido penetrar en un ámbito antes reservado en exclusiva 
al Estado central. Y debe añadirse que esa intervención autonómica ha sido, por lo común, para bien, pero que, inevitablemente, adolecía de la carencia de unos mecanismos de coordinación cuando las facultades ordinarias no fueran suficientes.

El Estado autonómico se asienta sobre el deber genérico de colaboración, que se traduce en técnicas de cooperación voluntaria entre instancias equiordenadas. Pero esa colaboración voluntaria puede no ser suficiente cuando es precisa una potestad directiva consustancial al poder de coordinación. En el marco del Estado autonómico, el estado de alarma ocupa un espacio difuso entre las potestades ordinarias de la protección civil y las extraordinarias de los estados de emergencia (excepción y sitio) que tienen a su alcance la suspensión del ejercicio de determinados derechos fundamentales. Si RD alarma-1 permitió considerar el estado de alarma como una técnica para asegurar la unidad de mando y RD alarma-2 como una vía para salvar los problemas que pudiera plantear la intervención judicial previa a la aplicación de medidas sanitarias, con RD alarma-3 se intenta el recurso al estado de emergencia en el contexto del Estado autonómico, aprovechando la experiencia de gestión ordinaria autonómica y haciendo uso de una instancia de coordinación ya acreditada: el Consejo Interterritorial del Sistema Nacional de Salud. Con todo, la nueva manifestación del estado de alarma no deja de merecer ciertos reparos, tanto en lo que se refiere a su vigencia como en lo que atañe a la atribución de la condición de autoridades competentes delegadas a los presidentes autonómicos (y de las ciudades autónomas de Ceuta y Melilla).

\section{A) La vigencia del nuevo estado de alarma}

La primera de las novedades del nuevo estado de alarma, su prórroga por seis meses, no figuraba en el texto originario de RD alarma-3 (Real Decreto 926/2020, de 25 de octubre), cuyo artículo 4 avanzó el instante final de vigencia del estado de emergencia en las 00:00 horas del día 9 de noviembre, "sin perjuicio de las prórrogas que puedan establecerse". La utilización del plural invitaba a pensar que, como ya sucediera con RD alarma-1, el Gobierno habría de acudir al Congreso de los Diputados para, previa rendición de cuentas, solicitar la oportuna autorización para prorrogar la vigencia del estado de emergencia declarado. Esta forma de actuar era acorde con la lógica institucional y de relación entre poderes propia de una Monarquía parlamentaria (art. 1.3 CE), pero no ha sido la seguida en esta ocasión. 
A decir verdad, el artículo 14 de RD alarma-3 ya anticipaba otra forma de actuar al indicar que quien debía rendir cuentas al Congreso no era el Presidente del Gobierno sino el Ministro de Sanidad y que esa rendición de cuentas no tendría lugar en el pleno de la Cámara sino ante la Comisión de Sanidad y Consumo. Bien pudiera pensarse, no obstante, que era otra modalidad de información a la instancia de cuya confianza depende el Gobierno, no vinculada al otorgamiento de la autorización para la prórroga.

Finalmente, no imperó esta interpretación y la información no era complementaria sino sustitutiva, porque así lo quiso el Congreso de los Diputados, que en su resolución de 29 de octubre autorizó la prórroga del estado de alarma desde las 00:00 horas del día 9 de noviembre hasta las 00:00 horas del día 9 de mayo de 2021, como así hizo el Real Decreto 956/2020, de 3 de noviembre. Además, impuso una modificación del régimen de información al propio Congreso, de modo que el Presidente del Gobierno solo había de comparecer ante el Pleno cada dos meses, encargándose el Ministro de Sanidad de esta labor de relación ante la Comisión de Sanidad Consumo, pero no con periodicidad quincenal como establecía RD alarma-3, sino mensual.

Además, el Congreso de los Diputados introdujo una novedad relevante para la gestión conjunta del estado de alarma, al prever que transcurridos cuatro meses de vigencia de esta prórroga, la conferencia de presidentes autonómicos podrá formular al Gobierno una propuesta de levantamiento del Estado de Alarma, previo acuerdo favorable del Consejo Interterritorial del Sistema Nacional de Salud a la vista de la evolución de los indicadores sanitarios, epidemiológicos, sociales y económicos (apartado 3 del artículo 14 RD alarma-3, en la redacción dada por el Real Decreto 956/2020). Debe entenderse que el precepto nos remite a la figura de las recomendaciones de la Conferencia, para cuya adopción, de conformidad con el artículo 6.3 de su Reglamento interno (publicado en el "Boletín Oficial del Estado" núm. 305, de 19 de diciembre de 2009), se requiere el voto favorable del Presidente del Gobierno y dos tercios de los presidentes autonómicos y de las ciudades autónomas de Ceuta y Melilla (es decir, un total de trece).

De modo que el estado de alarma tiene una vigencia máxima de seis meses, revisable a los cuatro meses siempre que así lo soliciten de consuno el Presidente del Gobierno y trece presidentes autonómicos o de las ciudades autónomas de Ceuta y Melilla. Parece razonable dar entrada en la gestión del 
estado de alarma a las comunidades autónomas, pero resulta más discutible que el Congreso de los Diputados renuncie a ejercer sus facultades de fiscalización en los términos en que lo ha hecho con la prórroga de RD alarma-3.

En la lógica de la regulación del estado de alarma se aprecia cómo la concentración de poderes extraordinarios en el Gobierno tiene como correlato imprescindible un control más intenso por parte de la Cámara parlamentaria de cuya confianza emana la dirección del Gobierno. Esa intensidad se concreta en la exigencia de comparecencia periódica para la concesión de sucesivas prórrogas del instrumento habilitante de los poderes extraordinarios. Cuando se acumulan todas las prórrogas hipotéticas en una sola y se extiende el estado de alarma durante seis meses, atribuyendo además a una instancia intergubernamental la posibilidad de anticipar el cese del estado de emergencia en cuestión, podemos concluir que el contrapeso parlamentario imprescindible en una "Monarquía parlamentaria" se ha desvanecido por completo.

B) Los presidentes autonómicos, autoridades competentes delegadas

De acuerdo con el artículo 7 LOEAES, declarado el estado de alarma, la autoridad competente será el Gobierno o, por delegación de este, el Presidente de la Comunidad Autónoma cuando la declaración afecte exclusivamente a todo o parte del territorio de una Comunidad. Y, de acuerdo con el artículo 2.2 $\mathrm{RD}$ alarma-3, en cada comunidad autónoma y ciudad con Estatuto de autonomía, la autoridad competente delegada será quien ostente la presidencia de la comunidad autónoma o ciudad con Estatuto de autonomía, en los términos establecidos en este real decreto.

Lo dispuesto en el artículo 7 LOEAES asegura la unidad de mando cuando la situación de emergencia no tiene alcance supraautonómico, algo que no se garantiza con lo establecido en RD alarma-3. Ciertamente, el precepto asegura la unidad de mando intraautonómica, en los límites no siempre precisos de la LOEAES, pero no garantiza la coordinación propia de esa unidad de mando que parecería uno de los objetivos perseguidos en todo caso con la declaración del estado de alarma.

La razón de esta delegación, que contrasta con la recogida en RD alarma-1 debe buscarse en el artículo 2.3 de ese mismo RD alarma 3: 
Las autoridades competentes delegadas quedan habilitadas para dictar, por delegación del Gobierno de la Nación, las órdenes, resoluciones y disposiciones para la aplicación de lo previsto en los artículos 5 a 11. Para ello, no será precisa la tramitación de procedimiento administrativo alguno ni será de aplicación lo previsto en el segundo párrafo del artículo 8.6 y en el artículo 10.8 de la Ley 29/1998, de 13 de julio, reguladora de la Jurisdicción Contencioso-administrativa.

La delegación conlleva una habilitación que frecuentemente altera el régimen de distribución de potestades resultante del Derecho autonómico y lo hace con el objetivo confeso de evitar la necesidad de acudir a la autorización o ratificación judicial. Adviértase, en todo caso, que la instancia habilitada es la autoridad competente delegada, esto es, el presidente autonómico, pero no el Gobierno que preside, que actuará en todo caso en el ejercicio de sus facultades ordinarias. Si se interpreta el artículo 2.3 RD alarma-3 como un precepto que confiere potestad reglamentaria extraordinaria a los presidentes autonómicos praeter legem (en este caso, al margen de las disposiciones estatutarias y legales que en cada comunidad autónoma regulen el ejercicio de la potestad reglamentaria), habrá que preguntarse si estamos ante una auténtica delegación de una potestad de creación de Derecho, que es de suyo indelegable, o ante una habilitación. Si es lo primero, la competencia jurisdiccional para su fiscalización corresponderá al Tribunal Supremo, instancia competente para conocer de los recursos contencioso-administrativos contra los actos y disposiciones del Consejo de Ministros (art. 58.1 LOPJ). Si, por el contrario, no se confunde la habilitación con la delegación, el conocimiento de tales recursos corresponderá, en única instancia, a los tribunales superiores de justicia [art. 74.1 a) y b) LOPJ].

Ahora bien, este deslinde de competencias jurisdiccionales no resuelve dos problemas. El primero de ellos radica en determinar hasta qué punto el decreto de declaración del estado de alarma puede conceder la habilitación, a instancias ajenas al Gobierno de la Nación, de poderes exorbitantes. Y por tal debemos considerar la potestad reglamentaria ad extra atribuida a unos presidentes autonómicos que carecen de ella. Una cosa es que los decretos de declaración de los estados de emergencia puedan suspender pro tempore la aplicación de determinadas normas, y otra bien distinta es que puedan alterar 
el régimen autonómico de potestades públicas consagrado en el bloque de constitucionalidad.

El segundo problema tiene que ver con la impugnación de los decretos emanados de los gobiernos autonómicos. El órgano colegiado consejo de gobierno no es autoridad competente delegada en el estado de alarma, porque no lo puede ser ex artículo 7 LOEAES y porque el RD alarma-3 no le ha atribuido esa condición. Si el consejo de gobierno autonómico no actúa por delegación, sino que ejerce poderes propios, el régimen de impugnación de sus actos y acuerdos no se verá afectado y la competencia jurisdiccional para el conocimiento de los recursos contencioso-administrativos que puedan promoverse seguirá correspondiendo a los tribunales superiores de justicia.

Por otro lado, si los gobiernos autonómicos continúan, en cuanto tales, actuando en el ejercicio de sus competencias ordinarias, nada impide el pleno control parlamentario de su actividad. No parece, sin embargo, que esa plenitud de control parlamentario esté siendo la norma, tampoco en el ámbito autonómico.

C) El alcance de la delegación

El RD alarma-3 establece las siguientes limitaciones: (a) de movilidad, por franjas horarias, popularizada como "toque de queda" (art. 5) y de movilidad interterritorial (art. 6), y (b) de reunión en lugares tanto públicos como privados (art. 7) y en lugares de culto (art. 8).

Ahora bien, por referencia al texto del RD alarma-3 vigente al momento de redactar estas líneas (antes de la modificación por el RD 956/2020 regía en todo caso el toque de queda), debe advertirse que la vigencia de estas limitaciones dependerá de que "la autoridad competente delegada así lo determine" (art. 9). Pueden, además, esas mismas autoridades delegadas "modular, flexibilizar y suspender" la aplicación de estas medidas, "a la vista de la evolución de los indicadores sanitarios, epidemiológicos, sociales, económicos y de movilidad, previa comunicación al Ministerio de Sanidad y de acuerdo con lo previsto en el artículo 13" (art. 10). Habrá que entender que esa decisión de modulación, flexibilización o suspensión de las medidas podrá adoptarse durante la vigencia de estas, que no puede ser inferior a siete días 
naturales (párrafo primero in fine del art. 9), pues en otro caso la facultad conferida carece de objeto.

La mención expresa del artículo 13 permite identificar el instrumento de coordinación sobre el que descansa la coherencia interterritorial de las medidas: el Consejo Interterritorial del Sistema Nacional de Salud:

Con la finalidad de garantizar la necesaria coordinación en la aplicación de las medidas contempladas en este real decreto, el Consejo Interterritorial del Sistema Nacional de Salud, bajo la presidencia del Ministro de Sanidad, podrá adoptar a estos efectos cuantos acuerdos procedan, incluidos, en su caso, el establecimiento de indicadores de referencia y criterios de valoración del riesgo.

EI RD alarma-3 aprovecha así la experiencia del Consejo Interterritorial creado por la Ley 16/2003, de 28 de mayo, de cohesión y calidad del Sistema Nacional de Salud, y definido por el artículo 69.1 de este texto legal como "órgano permanente de coordinación, cooperación, comunicación e información". Sucede, sin embargo, que la función coordinadora del Consejo Interterritorial tiene un carácter estrictamente sectorial $-\mathrm{y}$, en este caso, reconduce a lo previsto en el artículo $71.3 \mathrm{~g}$ ) de esa misma Ley, que le atribuye la labor de "coordinar aquellos aspectos relacionados con acciones sanitarias del Sistema Nacional de Salud que dispongan las leyes o que, de acuerdo con su naturaleza, precisen de una actuación coordinada de las Administraciones sanitarias públicas"-. Mal puede hablarse de coordinación previa y desde los aspectos relacionados con las "acciones sanitarias" si la modulación, suspensión o flexibilización se fundamenta en datos "sociales, económicos [o] de movilidad". La coordinación sectorial como trámite previo del procedimiento no parece que garantice suficientemente la coherencia final de las decisiones.

\section{CONCLUSIONES}

El contraste entre los distintos estados de alarma declarados en el último año pone de manifiesto la ductilidad de la figura. Si RD alarma-1 permitió garantizar la unidad de mando para hacer frente a la pandemia, aun a riesgo de poner en cuestión el límite infranqueable de la imposibilidad de suspender el ejercicio de algunos derechos fundamentales, RD alarma-3 ha servido para intentar 
adecuar este estado de emergencia a las características del Estado autonómico. Se ha pasado de un estado de emergencia de efectos inmediatos, pero vigencia limitada en el tiempo, a otro de vigencia casi ilimitada pero cuyos efectos quedan sujetos a la condición suspensiva de la decisión de unas autoridades competentes delegadas, en las que, inopinadamente, se ha delegado el núcleo esencial del estado de alarma. EI RD alarma-3 puede considerarse una ley habilitante de poderes a los presidentes autonómicos. Puede que la solución sea sensata, pero hubiera debido venir precedida de una reforma de la LOEAES, cuya necesidad, por otro lado, se hizo manifiesta durante la vigencia de RD alarma-1.

El gran ausente durante toda esta crisis ha sido el Parlamento. En particular, se desaprovechó entre la primera y la segunda ola de la pandemia, que brindaba una gran ocasión para la reforma y actualización de la legislación sanitaria. También parece haberse olvidado que la habilitación de las facultades extraordinarias que supone el estado de emergencia tiene como contrapartida una mayor intensidad del control parlamentario. La concesión de una única prórroga por seis meses, como ha sucedido en RD alarma-3 presta flaco servicio a una "Monarquía parlamentaria" pues transmite la sensación de que el Parlamento se desentiende de la mayor crisis que ha sufrido España bajo la vigencia de la Constitución de 1978.

El Estado autonómico ha transformado de tal manera la forma de gestionar y de hacer política que las soluciones ideadas por la LOEAES han quedado claramente superadas. La recentralización de competencias tiene un coste elevadísimo en calidad de prestación de los servicios públicos y entraña serios problemas de gestión. Se ha hecho preciso, por ello mismo, idear fórmulas de colaboración entre poderes territoriales para la gestión de la crisis. Que estas fórmulas puedan adolecer de carencias en punto a la necesaria coherencia de las medidas articuladas no puede sorprender, pero merece una reflexión a fin de actualizar nuestro Derecho constitucional de emergencia.

Convendría, en fin, repensar la categoría misma del estado de alarma. Se trata de una figura creada por la Constitución, que no la dotó de un régimen jurídico definido, más allá del límite negativo consistente en la imposibilidad de acordar la suspensión de ningún derecho fundamental. No puede decirse, además, que su regulación legal haya soportado bien el paso del tiempo: tras la aprobación de la LOEAES nuestro aparato administrativo conoció una transformación 
fundación

Manuel Giménez Abad

deEstudios Parlamentarios ydelEstado Autonómico

radical a la que no se han adecuado las disposiciones de este texto legal y, acaso como consecuencia indirecta de esa generalización del autogobierno, se desarrolló un nuevo sector de acción administrativa, la protección civil, que ha permitido el alumbramiento y desarrollo de técnicas que quizás hayan dejado obsoletos algunos extremos de la regulación de la LOEAES. 